\title{
A Characterization Study of Initial $\gamma$ ' Phase Formation Produced by Microwave
}

\author{
J.L. Bernal-Ponce ${ }^{1}$, A. García-Barrientos ${ }^{1}$, and L. Béjar-Gómez ${ }^{2}$, A. Medina-Flores ${ }^{2}$, E. Vera ${ }^{1}$ \\ ${ }^{1}$ Universidad Politécnica de Pachuca, Carretera Pachuca-Cd. Sahagún, km 20, Ex-Hacienda de Santa \\ Bárbara Municipio de Zempoala, Hidalgo, CP 43830, México \\ ${ }^{2}$ UMSNH. Ciudad Universitaria, Morelia, Michoacán. 58000. México
}

A study of the initial states during the postdicharge nitriding process by microwave is set. In this process unlike the process of nitriding for ammonium gas, where the process of dissociation of the molecule involves reacting NH3 catalytic surface of the iron piece, the excitation of the nitrogen molecule is performed by collision between an electron and N2 molecule generating the reactive species with vibrational levels under 45, described by the following expression: N2 (X, $v \leq 45)$, [1].

The active neutral species generated in the discharge and transported to the piece developed a concentration gradient from the surface. The adsorption process generated by physisorption and chemisorption in the substrate develop an initial concentration profile [2-4] and for long treatment time, results in the development of compact layers.

In particular, in the postdischarge nitriding process, the production of neutral active species and the transport of mass into the solid are related to kinetics reaction that leads to the very rapid precipitation of nitrides in the surface.

Specimens of ARMCO Iron (200 mm diameter; Mn, 880 ppm; C and P, 220 ppm; $0.23 \mathrm{Si}, \mathrm{S}, 150$ ppm) were nitrided during short period of times. The sample surface to be exposed was polished down to 3 $\mu \mathrm{m}$ and thoroughly cleaned in an acetone ultrasonic bath before nitriding. Nitriding experiments were carried out in a post-discharge flow of plasma generated in the microwave reactor, which is described in previous works [5].

Figures 1(a-c) shows optical micrographs from the specimens treated by postdicharge nitriding process. Specimen treated for 5 seconds (fig 1a), 25 s. (fig. 1b) and 180 s. (fig. 1c) respectively. Fig. 1d shows a Scanning Electron Microscopy from the sample nitrided for $180 \mathrm{~s}$. The X-ray diffraction (fig. 2) spectra shows that the formation of the $\gamma^{\prime}-\mathrm{Fe} 4 \mathrm{~N}$ on the top of the surface occurs at short treatment time. On other hand, the intensity of theFe $4 \mathrm{~N}$ diffraction lines increases with respect to time of treatment.

\section{References:}

[1] A.N. Wright, C.A. Wrinkler, Active Nitrogen, Academic Press, New York, 1968

[2] O. Salas, U. Figueroa, M. Palacios. J. Oseguera. Surf. Coat. Technol. 86-87 (1996) 332337.

[3] J.L Bernal, O. Salas, U. Figueroa, J. Oseguera. Early stages of $\gamma^{\prime}-F e 4 N 1-x$ nucleation and growth in a post-discharge nitriding reactor. Surf. Coat. Technol. 177-178 (2004) 665-670.

[4] J.L. Bernal. Ph.D. Thesis, ITESM-CEM. México, 2005.

[5] J. Oseguera and et al. Surf. Coat. Technol. 94-95 (1997) 587 


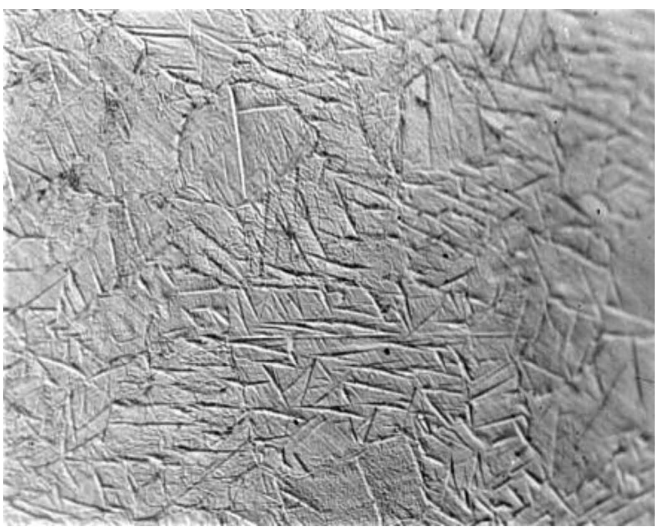

Fig. 1a

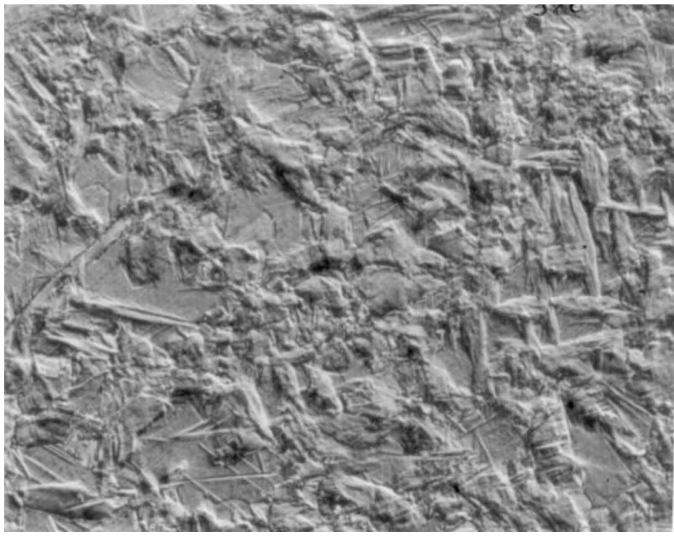

Fig. 1c

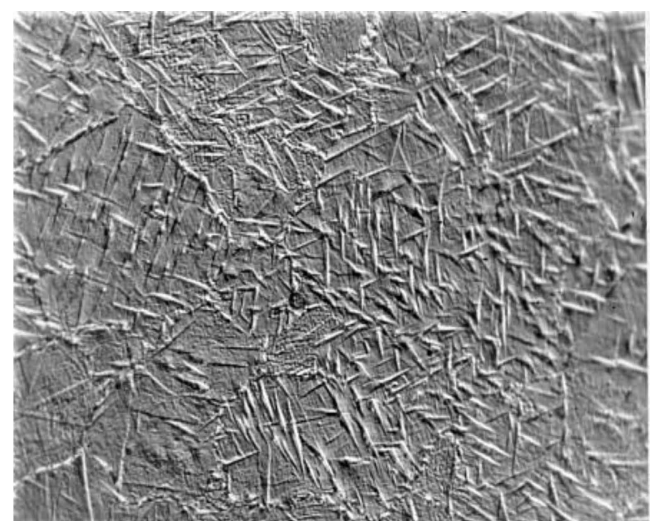

Fig. 1b

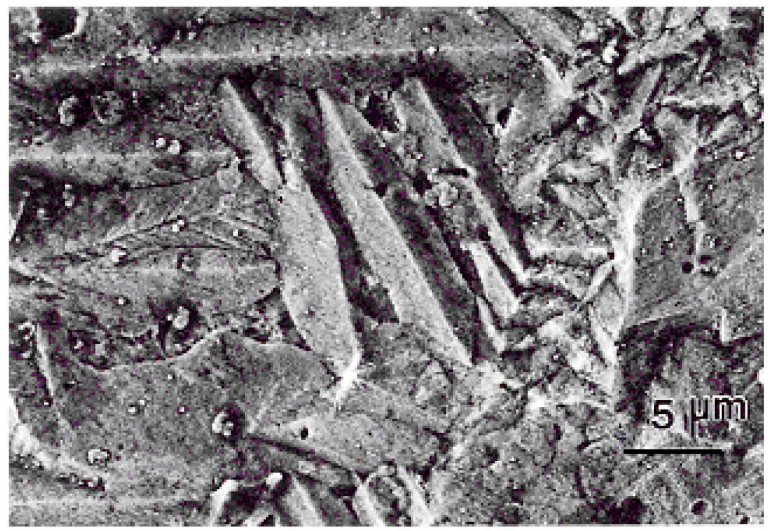

Fig. 1d

Figures 1(a-c) shows optical micrographs from the specimens treated by postdicharge nitriding process. Specimen treated for 5 seconds (fig 1a), 25 s. (fig. 1b) and 180 s. (fig. 1c) respectively. Fig. 1d shows a SEM image from the sample nitrided for $180 \mathrm{~s}$.

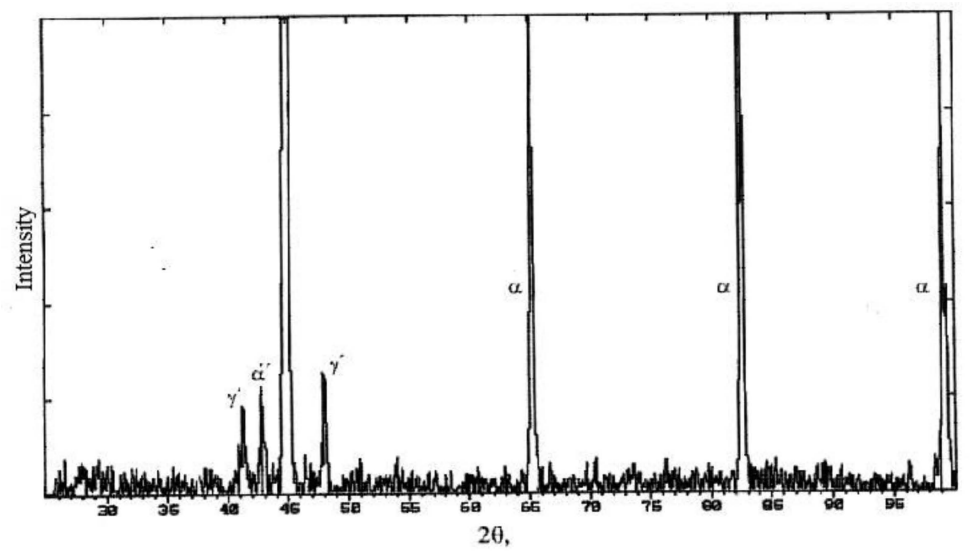

Fig. 2

Fig. 2. The X-ray diffraction spectra shows the $\gamma^{\prime}-\mathrm{Fe} 4 \mathrm{~N}$ phase for the sample nitrided for $180 \mathrm{~s}$. 